\section{ORIGINAL RESEARCH}

H.-S. Kang

B.J. Kwon

J.E. Kim

M.H. Han

\title{
Preinterventional Clopidogrel Response Variability for Coil Embolization of Intracranial Aneurysms: Clinical Implications
}

BACKGROUND AND PURPOSE: Thromboembolism is one of the most serious complications in coi embolization for intracranial aneurysms, and antiplatelet premedication may reduce this complication. However, interindividual variation exists in the efficacy of CPG. This study sought to elucidate the clinical implications of preinterventional CPG response variability in patients who undergo coil embolization for intracranial aneurysms.

MATERIALS AND METHODS: CPG premedication was given to 186 consecutive patients with 209 aneurysms who underwent elective coil embolization, and the response to the premedication was measured by a point-of-care antiplatelet function test (VerifyNow assay). Patients were stratified into 4 quartiles according the test results, and their correlation with the occurrence of periprocedural complications was analyzed. The contribution of a variety of variables to the high PRU was also tested.

RESULTS: In this cohort, rates of thromboembolic events and all adverse events were $7.5 \%$ and $9.1 \%$, respectively. The quartiles of the P2Y12 reaction unit of the ADP channel (PRU) showed a significant tendency toward thromboembolic events $(P=.013)$ and all procedure-related adverse events $(P=$ .009), while those of the BASE and percentage inhibition did not. Thromboembolic events occurred in $17.0 \%$ and procedure-related adverse events, in $21.3 \%$ of the patients in the fourth quartile. Female sex was the only significant factor related to the fourth quartile of PRU in the multiple logistic regression analysis $(P=.014)$.

CONCLUSIONS: Procedure-related thromboembolic events occurred more frequently in patients in the upper quartile with higher PRU, especially in the fourth quartile. Further study including a large number of patients is expected to confirm this finding.

ABBREVIATIONS: ADP = adenosine diphosphate; ANOVA $=$ analysis of variance; $\mathrm{BASE}=$ isothrombin receptor activating peptide channel; $C P G=$ clopidogrel; $H D L=$ high-density lipoprotein; $\mathrm{LDL}=$ low-density lipoprotein; $\mathrm{PRU}=$ residual platelet reactivity; $\mathrm{ROC}=$ receiver-operating characteristic; SPSS $=$ Statistical Package for the Social Sciences

$\mathbf{T}^{\mathrm{T}}$ hromboembolism is one of the most serious complications in coil embolization for intracranial aneurysms, ${ }^{1-5}$ and antiplatelet premedication may reduce this complication. ${ }^{6,7}$ CPG is a P2Y12 ADP receptor antagonist ${ }^{5,8}$ and, through a series of clinical trials, has become a standard regimen in patients at risk of ischemic stroke and myocardial infarction. ${ }^{9-11}$ However, there is a concern over increased risk of bleeding with combination antiplatelet therapy including CPG. ${ }^{12,13} \mathrm{On}$ the other hand, the efficacy of prophylactic CPG therapy is variable among patients, and resistance to the antiplatelet therapy is considered the major cause of the variable response. ${ }^{14,15}$ The influence of high pretreatment platelet reactivity on the outcome of patients with intracranial aneurysms treated with coil embolization is not yet well-established, to our knowledge. This study sought to elucidate the clinical implication of preinterventional CPC response variability in patients who undergo coil embolization for intracranial aneurysms.

Received November 19, 2009; accepted after revision January 13, 2010.

From the Departments of Neurosurgery (H.-S.K., J.E.K., M.H.H.) and Radiology (M.H.H., B.J.K.), Seoul National University College of Medicine, Seoul, Korea

Please address correspondence to Moon Hee Han, MD, PhD, Department of Radiology, Seoul National University Hospital, 28 Yongon-dong, Chongno-gu, Seoul 110-744, Korea; e-mail: hanmh@snuh.org

DOI 10.3174/ajnr.A2051

\section{Materials and Methods}

\section{Patient Population}

Since March 2006, CPC has been administered to patients with unruptured intracranial aneurysms before coil embolization in our institution. Since October 2008, we have measured the platelet reactivity after CPG premedication with a point-of-care antiplatelet function test (VerifyNow; Accumetrics, San Diego, California). We reviewed 186 consecutive patients with 209 aneurysms (116 internal carotid artery aneurysms, 46 anterior cerebral artery aneurysms, 28 middle cerebral artery aneurysms, and 19 posterior circulation aneurysms) who underwent the platelet activity measurement and elective coil embolization in our prospectively collected data base for neurointerventional procedures.

The baseline clinical and laboratory characteristics of the patients are presented in Table 1. "Nonsmokers" were defined as those who never smoked, and "smokers" included current and past smokers who have ever smoked 10 cigarettes per day for at least 1 year. Typically, a 300-mg loading dose of CPG was given the day before the procedure, and an additional $75 \mathrm{mg}$ of CPG was given on the morning of the procedure in most cases $(n=165,89 \%)$. Some patients had been taking antiplatelet agents other than CPG $(n=29)$. For chronic users of CPG, only a maintenance dose $(75 \mathrm{mg})$ was administered without loading ( $n=21,11 \%)$. Among chronic users, 11 patients had been taking aspirin as well. After the embolization procedure, an antiplatelet agent was administered orally for $\geq 1$ week, depending on 


\begin{tabular}{lr}
\hline \multicolumn{1}{l}{ Table 1: Patients' clinical and laboratory characteristics $(\boldsymbol{n}=\mathbf{1 8 6})^{\mathbf{a}}$} \\
\hline Characteristic & \\
\hline Sex, male/female & $57: 129(1: 2.3)$ \\
Age (yr) & $58.3 \pm 10.2$ \\
Body weight (Kg) & $63.6 \pm 10.7$ \\
Hypertension & $94(51 \%)$ \\
Diabetes mellitus & $15(8 \%)$ \\
Statin use & $31(17 \%)$ \\
Smoking & \\
Smoker & $36(19 \%)$ \\
$\quad$ Nonsmoker & $150(81 \%)$ \\
Alcohol intake & $36(19 \%)$ \\
Hematocrit level (\%) & $38.2 \pm 4.3$ \\
Platelet count ( $\left.\times 10^{3} / \mu L\right)$ & $227 \pm 60$ \\
Total cholesterol level (mg/dL) & $181.1 \pm 36.8$ \\
Triglyceride level (mg/dL) & $150.3 \pm 85.6$ \\
HDL cholesterol level (mg/dL) & $51.1 \pm 17.5$ \\
LDL cholesterol level (mg/dL) & $109.0 \pm 32.5$ \\
Mode of medication & \\
CPG loading (300 mg) only & $136(73 \%)$ \\
Previous other antiplatelet medication plus & $29(16 \%)$ \\
CPG loading & \\
Continued CPG medication without loading & $21(11 \%)$ \\
\hline
\end{tabular}

a All the continuous variables are presented as mean \pm SD.

the presence of underlying atherosclerotic stenosis or protruded coil loops at the end of the procedure, or the stent placement during coil embolization. For example, patients who had a stent placed during the procedure were prescribed CPG for 1 month and the use of aspirin was prescribed for an indefinite period.

\section{Coil Embolization Procedures and Procedure-Related Complications}

Endovascular coil embolization was performed by using a standardized protocol in a neuroangiography suite, as described previously. ${ }^{16,17}$ General anesthesia was induced during most sessions. Systemic anticoagulation with heparin was used from the beginning of the procedure. Heparin was usually administered as a 3000 -IU bolus intravenously just after the introducer sheath was inserted, followed by the administration of $1000 \mathrm{IU} / \mathrm{h}$. A simple coiling procedure (composed of a single microcatheter placement and coil deployment), a multiple-microcatheter technique, ${ }^{18,19}$ a balloon remodeling technique, ${ }^{20}$ and stent-supported coil embolization ${ }^{21}$ were used at the discretion of the operator.

The procedure-related thromboembolism was defined as thrombus formation and/or a distal embolism observed during the procedure or clinically recognized ischemic deficits that occurred within 60 days of the procedure. ${ }^{5,7}$ The procedure-related aneurysm perforation included both the "leak" and "nonleak" types. ${ }^{22}$ The former was defined as a demonstration of extra-aneurysmal contrast material, and the latter was defined as device extrusion from an aneurysm without contrast leakage.

\section{Blood Sample Acquisition and Platelet Activity Measurement}

Whole blood was obtained before the coil embolization procedure by puncture of the antecubital vein. Blood was placed into 1.8-mL-draw plastic Vacuette tubes (Greiner, Monroe, North Carolina) containing $3.2 \%$ sodium citrate, following a $5-\mathrm{mL}$ discard, as previously described. ${ }^{23}$ Residual platelet reactivity on CPG therapy was measured by using the VerifyNow P2Y12 assay (Accumetrics), a turbidimetricbased optical detection system that measures platelet aggregation. ${ }^{23,24}$
This system measures platelet aggregation as an increase in light transmittance and produces 3 values, including BASE, PRU, and percentage inhibition. BASE is a platelet reaction unit measured after stimulation with an isothrombin-receptor-activating peptide and serves as an estimate of baseline platelet reactivity. PRU is measured from the channel stimulated with $20 \mu \mathrm{mol}$ of ADP, reflecting residual P2Y12 receptor activity. Therefore, a high PRU value indicates less effectiveness of CPG therapy. Percentage inhibition is a calculated value from a formula: percentage inhibition $=($ BASE - PRU $) /$ BASE $\times 100$. In this study, patients were stratified into 4 quartiles according the test results, and their correlation with occurrence of periprocedural complications was analyzed. The contribution of a variety of clinical (sex, age, body weight, mode of CPG premedication, hypertension, diabetes, statin usage, smoking habit, alcohol intake) and laboratory variables (hematocrit, platelet count, total cholesterol, triglyceride, HDL cholesterol, LDL cholesterol) to the high residual platelet reactivity was also tested.

\section{Statistical Analyses}

An unpaired Student $t$ test, 1-way ANOVA, Tukey-Kramer multiple comparison test, and the $\chi^{2}$ test for trends were performed with by using GraphPad InStat (Version 3.05 for Windows 95/NT; GraphPad Software, San Diego, California). Quartile values and histograms were produced with the SPSS (Version 13.0 for Windows; SPSS, Chicago, Illinois). Logistic regression analysis was also performed with SPSS to find factors related to high PRU values. Variables with $P$ values $<.10$ in the simple logistic regression analysis were chosen as the variables for multiple logistic regression analysis. The ability of the test to discriminate between patients with and without a procedure-related thromboembolic event was evaluated by ROC curve analysis by using SPSS. The optimal cutoff value was calculated by determining the PRU value providing the greatest sum of sensitivity and specificity. $P$ values $<.05$ were considered significant in all analyses.

\section{Results}

For this study population $(n=186)$, procedure-related adverse events occurred in 9.1\% (17/186). These comprised 14/ $186(7.5 \%)$ thromboembolic events and 3/186 (1.6\%) procedural aneurysmal perforations ( 1 leak type and 2 nonleak type perforations). No patient had thromboembolism and aneurysmal perforation simultaneously. Among the 14 thromboembolic events, there were 9 cases of thrombi formation observed during the interventional procedures, 3 cases of acute symptomatic ischemic lesions without angiographic abnormality (5-24 hours after the procedures), and 2 cases of delayed symptomatic thromboembolism (11-32 days after embolization). All the thrombi found during the procedures were treated with intra-arterial tirofiban infusion $(n=8)$ or extended heparinization $(n=1)$ and did not produce any neurologic symptoms. There was no procedure-related permanent morbidity or mortality.

The mean values of test results were the following: BASE of $361.7 \pm 52.8$, PRU of $276.9 \pm 78.0$, and percentage inhibition of 23.1 \pm 20.1 . All the histograms of test results (BASE, PRU, and percentage inhibition) showed bell-shaped distributions. When quartiles of each variable (BASE, PRU, and percentage inhibition) were tested in relation to procedure-related adverse events, only those of PRU were found to be significant (Table 2). Thromboembolic events increased from $4.3 \%$ in the first quartile and $2.2 \%$ in the second quartile to $6.5 \%$ in the 
Table 2: Frequency of procedure-related adverse events according to PRU

\begin{tabular}{|c|c|c|c|c|}
\hline Quartile (No.) & PRU & Thromboembolic Events & $\begin{array}{c}\text { Procedure-Related Aneurysmal } \\
\text { Perforations }\end{array}$ & $\begin{array}{c}\text { All Procedure-Related Adverse } \\
\text { Events }\end{array}$ \\
\hline 1st (47) & $<240$ & $2(4.3 \%)$ & $1(2.1 \%)$ & $3(6.4 \%)$ \\
\hline 2nd (46) & $240-284$ & $1(2.2 \%)$ & $0(0 \%)$ & $1(2.2 \%)$ \\
\hline 3rd (46) & $285-332$ & $3(6.5 \%)$ & $0(0 \%)$ & $3(6.5 \%)$ \\
\hline 4th (47) & $>332$ & $8(17.0 \%)$ & $2(4.3 \%)$ & $10(21.3 \%)$ \\
\hline$P$ value ${ }^{\mathrm{a}}$ & & .013 & .605 & .009 \\
\hline
\end{tabular}

${ }^{\mathrm{a}} \chi^{2}$ test for trends.

\begin{tabular}{|c|c|c|}
\hline Clinical and Laboratory Variables & $P$ & PRU \\
\hline Sex (male) & $<.001$ & $244 \pm 68$ vs $291 \pm 78$ \\
\hline Age (younger than 65 years) & .028 & $268 \pm 80$ vs $295 \pm 72$ \\
\hline Body weight $(\geq 60 \mathrm{Kg})$ & .031 & $267 \pm 78$ vs $292 \pm 76$ \\
\hline CPG medication ( $\geq 7$ days) & .003 & $230 \pm 96$ vs $283 \pm 74$ \\
\hline Combination antiplatelet medication (yes) & .175 & $263 \pm 83$ vs $281 \pm 76$ \\
\hline Hypertension (no) & .745 & $275 \pm 78$ vs $278 \pm 78$ \\
\hline Diabetes mellitus (yes) & .184 & $251 \pm 99$ vs $279 \pm 76$ \\
\hline Statin use (no) & .198 & $274 \pm 78$ vs $293 \pm 77$ \\
\hline Smoking status (current or past smoker) & .071 & $256 \pm 73$ vs $282 \pm 79$ \\
\hline Alcohol intake (yes) & .157 & $260 \pm 76$ vs $280 \pm 78$ \\
\hline Hematocrit level ( $\geq 38 \%$ ) & .008 & $263 \pm 73$ vs $293 \pm 81$ \\
\hline Platelet count $\left(<227 \times 10^{3} / \mu \mathrm{L}\right)$ & .562 & $274 \pm 80$ vs $280 \pm 76$ \\
\hline Total cholesterol level $(<200 \mathrm{mg} / \mathrm{dL}$ ) & .232 & $273 \pm 80$ vs $288 \pm 71$ \\
\hline HDL cholesterol level ( $\geq 40$ mg/dL) & .225 & $275 \pm 79$ vs $292 \pm 69$ \\
\hline LDL cholesterol level ( $\geq 130 \mathrm{mg} / \mathrm{dL}$ ) & .608 & $273 \pm 75$ vs $280 \pm 78$ \\
\hline Triglyceride level (<200 mg/dL) & .091 & $274 \pm 77$ vs $299 \pm 72$ \\
\hline Procedure-related thromboembolism (no) & .061 & $274 \pm 78$ vs $318 \pm 54$ \\
\hline
\end{tabular}

value of 295 was identified as the optimal cutoff point to predict the events, with a sensitivity of $75 \%$ and a specificity of $57 \%$.

\section{Discussion}

Adequate inhibition of the platelet activity, as well as anticoagulation, is a principal concern for neurointerventional procedures, including coil embolization of intracranial aneurysms to prevent procedure-related adverse events. The VerifyNow system is one of convenient tools for measurement of platelet activity in response to CPG medication, and good correlations with ADP-induced platelet aggregation determined by using light transmittance aggregometry and vasodilator-stimulated phosphoprotein phosphorylation assay have been demonstrated. ${ }^{25-28}$ Until now various cutoff values of different parameters have been tested. ${ }^{23,29,30}$ When CPG resistance was defined as percentage inhibition $<40 \%, 43 \%-52 \%$ of patients were CPG-resistant in the previous studies. ${ }^{29,30}$ When we applied this criterion to our series of patients, the rate of CPG resistance amounted to $84 \%$ (157/186). However, the incidence of procedure-related thromboembolic events $(7.5 \%)$ was less than one-tenth of this number. Thus, we tried to find another viable criterion, the PRU value, which was found to be clinically applicable when we divided our patients into quartiles.

Thromboembolic events significantly increased from the first $(4.3 \%)$ and second (2.2\%) quartiles to the third (6.5\%) and fourth $(17.0 \%)$ quartiles $(P=.013)$, and the fourth quartile PRU cutoff value was 332 . While percentage inhibition reflects the individual patient's responsiveness to CPG treatment, PRU gives information on the residual platelet reactivity following antiplatelet treatment. For example, when a patient who is CPG-resistant demonstrates a high percentage inhibition value on the VerifyNow P2Y12 assay, he or she may show high or low PRU values based on the remaining platelet reactivity. In our study, percentage inhibition failed to reveal meaningful correlation with the outcome variables of procedure-related thromboembolic events or procedure-related complications. On the contrary, PRU was found to have a significant impact on the outcome variable. Several studies in the field of cardiology demonstrated that high PRU values were associated with increased periprocedural myocardial infarction as well as mortality after percutaneous coronary intervention. ${ }^{24,31}$

Regarding the mode of CPG administration, chronic use ( $\geq 7$ days) provided benefit in reducing platelet reactivity ( $\mathrm{Ta}$ ble 4). In our series, the chronic users had some reasons for the CPG prescription, including histories of previous cerebral infarction or coronary artery disease with or without percutaneous coronary intervention performed; otherwise we did give 


\begin{tabular}{lccc} 
Mode of Administration & BASE & $\begin{array}{c}\text { Percentage } \\
\text { Inhibition }\end{array}$ \\
\hline CPG loading (300 mg) only, 136 (73\%) & $360.8 \pm 51.8$ & $285.2 \pm 71.6$ \\
Previous other antiplatelet medication plus CPG loading (300 mg), $29(16 \%)$ & $358.8 \pm 63.0$ & $27.6 \pm 18.4$ \\
Continued CPG medication for $\geq 7$ days without loading, $21(11 \%)$ & $371.9 \pm 45.1$ & $24.5 \pm 19.2$ \\
$P$ value $^{\text {a }}$ & .6388 & $230.0 \pm 96.2$ & $.0091^{\mathrm{b}}$ \\
\hline
\end{tabular}

a One-way ANOVA.

b There was a significant difference between the first group and the third group on the Tukey-Kramer multiple comparison test $(P<.01)$.

\begin{tabular}{|c|c|c|}
\hline \multicolumn{3}{|c|}{$\begin{array}{l}\text { Table 5: Results of regression analysis for variables related to high } \\
\text { PRU (>332) }\end{array}$} \\
\hline & \multicolumn{2}{|c|}{$P$ Value } \\
\hline Variables & $\begin{array}{c}\text { Simple Logistic } \\
\text { Regression Analysis }\end{array}$ & $\begin{array}{l}\text { Multiple Logistic } \\
\text { Regression Analysis }^{\mathrm{a}}\end{array}$ \\
\hline Gender & .001 & .014 \\
\hline Age & .241 & \\
\hline Body weight & .009 & .547 \\
\hline Mode of CPG medication & .096 & .086 \\
\hline Combination therapy & .255 & \\
\hline Hypertension & .800 & \\
\hline Diabetes mellitus & .626 & \\
\hline Statin use & .598 & \\
\hline Smoking & .088 & .114 \\
\hline Alcohol intake & .373 & \\
\hline Hematocrit level & .049 & .169 \\
\hline Platelet count & .058 & .141 \\
\hline Total cholesterol level & .443 & \\
\hline Triglyceride level & .159 & \\
\hline HDL cholesterol level & .287 & \\
\hline LDL cholesterol level & .499 & \\
\hline
\end{tabular}

ariables with $P<0.10$ were entered into multivariate analysis to determine their independent association with high PRU.

CPG the day before the coil embolization at the time of admission. If we have confirmatory evidence that CPG medication does not add bleeding risk in patients with unruptured intracranial aneurysms, then we may favor extended duration of medication for them in the preinterventional period. When we performed regression analyses with variables in relation to a high PRU value ( $>332$ ), female sex was found to be the single significant factor (Table 5). A previous study also documented a similar tendency of different responses to $\mathrm{CPG}$ according to sex (men versus women, $200 \pm 77$ versus $220 \pm 82$ PRU, $P=$ $.041) .^{32}$ The authors speculated that sex-specific differences in the cytochrome P450 system could have an influence on the formation of active metabolites of CPG. ${ }^{32}$

What can be done in the high-risk patients in terms of antiplatelet premedication? We propose 2 solutions: 1 ) to increase the CPG dosage, and 2) to administer another antiplatelet agent. In a recent study comparing the impact of a high maintenance dose of CPG (150 mg/day) and the addition of cilostazol (a selective inhibitor of phosphodiesterase type 3), the latter was found to be superior in decreasing platelet aggregation and increasing percentage inhibition of $\mathrm{P} 2 \mathrm{Y} 12$ reaction units. ${ }^{33}$ Prasugrel, a third-generation thienopyridine, might be another option. This was found to be associated with significant reduction in rates of ischemic events, but with increased risks of major bleeding and fatal bleeding in patients with acute coronary syndromes. ${ }^{34}$ Temporary short-term administration of prasugrel during the periprocedural period might result in decreased procedure-related thromboembolic events in patients undergoing coil embolization for unruptured intracranial aneurysms.

Apart from our study, genetic analyses, including cytochrome $\mathrm{P} 450$ 2C19 polymorphisms, would be an alternative way to predict the CPG responsiveness. ${ }^{35-37}$ We need to choose the more cost-effective and timely way of predicting individual responses to antiplatelet prophylaxis. We might be able to restrict the patients being tested by using the VerifyNow P2Y12 assay before gene studies.

\section{Conclusions}

The VerifyNow P2Y12 assay seems to identify high-risk patients when we administer prophylactic antiplatelet agents before coil embolization of unruptured intracranial aneurysms. In our series, the patients in the fourth quartile PRU values (PRU > 332) showed a significantly higher rate of procedurerelated thromboembolic events. Further study including a larger number of patients is expected to confirm this finding.

\section{References}

1. Pelz DM, Lownie SP, Fox AJ. Thromboembolic events associated with the treatment of cerebral aneurysms with Guglielmi detachable coils. AJNR Am J Neuroradiol 1998;19:1541-47

2. Derdeyn CP, Cross DT 3rd, Moran CJ, et al. Postprocedure ischemic events after treatment of intracranial aneurysms with Guglielmi detachable coils. J Neurosurg 2002;96:837-43

3. Park HK, Horowitz M, Jungreis C, et al. Periprocedural morbidity and mortality associated with endovascular treatment of intracranial aneurysms. AJNR Am J Neuroradiol 2005;26:506-14

4. Ross IB, Dhillon GS. Complications of endovascular treatment of cerebra aneurysms. Surg Neurol 2005;64:12-19

5. Brooks NP, Turk AS, Niemann DB, et al. Frequency of thromboembolic events associated with endovascular aneurysm treatment: retrospective case series. J Neurosurg 2008;108:1095-100

6. Ries T, Buhk JH, Kucinski T, et al. Intravenous administration of acetylsalicylic acid during endovascular treatment of cerebral aneurysms reduces the rate of thromboembolic events. Stroke 2006;37:1816-21

7. Yamada NK, Cross DT 3rd, Pilgram TK, et al. Effect of antiplatelet therapy on thromboembolic complications of elective coil embolization of cerebral aneurysms. AJNR Am J Neuroradiol 2007;28:1778-82

8. Dorsam RT, Kunapuli SP. Central role of the P2Y12 receptor in platelet activation. J Clin Invest 2004;113:340-45

9. A randomised, blinded, trial of clopidogrel versus aspirin in patients at risk of ischaemic events (CAPRIE): CAPRIE Steering Committee. Lancet 1996; 348:1329-39

10. Yusuf S, Zhao F, Mehta SR, et al. Effects of clopidogrel in addition to aspirin in patients with acute coronary syndromes without ST-segment elevation. N Engl J Med 2001;345:494-502

11. Steinhubl SR, Berger PB, Mann JT 3rd, et al. Early and sustained dual oral antiplatelet therapy following percutaneous coronary intervention: a randomized controlled trial. JAMA 2002;288:2411-20

12. Diener HC, Bogousslavsky J, Brass LM, et al. Aspirin and clopidogrel compared with clopidogrel alone after recent ischaemic stroke or transient ischaemic attack in high-risk patients (MATCH): randomised, double-blind, placebocontrolled trial. Lancet 2004;364:331-37

13. Bhatt DL, Fox KA, Hacke W, et al. Clopidogrel and aspirin versus aspirin alone for the prevention of atherothrombotic events. N Engl J Med 2006; 354:1706-17

14. Gurbel PA, Bliden KP, Hiatt BL, et al. Clopidogrel for coronary stenting: re- 
sponse variability, drug resistance, and the effect of pretreatment platelet reactivity. Circulation 2003;107:2908-13

15. Serebruany VL, Steinhubl SR, Berger PB, et al. Variability in platelet responsiveness to clopidogrel among 544 individuals. J Am Coll Cardiol 2005;45:246-51

16. Kwon BJ, Han MH, Oh CW, et al. Anatomical and clinical outcomes after endovascular treatment for unruptured cerebral aneurysms: a single center experience. Interventional Neuroradiology 2002;8:367-76

17. Kwon BJ, Han MH, Oh CW, et al. Procedure-related haemorrhage in embolisation of intracranial aneurysms with Guglielmi detachable coils. Neuroradiology 2003;45:562-69. Epub 2003 Jul 8

18. Kwon OK, Kim SH, Kwon BJ, et al. Endovascular treatment of wide-necked aneurysms by using two microcatheters: techniques and outcomes in 25 patients. AJNR Am J Neuroradiol 2005;26:894-900

19. Kwon OK, Kim SH, Oh CW, et al. Embolization of wide-necked aneurysms with using three or more microcatheters. Acta Neurochir (Wien) 2006;148: 1139-45, discussion 1145. Epub 2006 Sep 29

20. Moret J, Cognard C, Weill A, et al. Reconstruction technic in the treatment of wide-neck intracranial aneurysms: long-term angiographic and clinical results—apropos of 56 cases [in French]. J Neuroradiol 1997;24:30-44

21. Higashida RT, Smith W, Gress D, et al. Intravascular stent and endovascular coil placement for a ruptured fusiform aneurysm of the basilar artery: case report and review of the literature. J Neurosurg 1997;87:944-9

22. Kwon BJ, Chang HW, Youn SW, et al. Intracranial aneurysm perforation during endosaccular coiling: impact on clinical outcome, initial occlusion, and recanalization rates. Neurosurgery 2008;63:676-83

23. Lee DH, Arat A, Morsi $\mathrm{H}$, et al. Dual antiplatelet therapy monitoring for neurointerventional procedures using a point-of-care platelet function test: a single-center experience. AJNR Am J Neuroradiol 2008;29:1389-94

24. Price MJ, Nayak KR, Barker CM, et al. Predictors of heightened platelet reactivity despite dual-antiplatelet therapy in patients undergoing percutaneous coronary intervention. Am J Cardiol 2009;103:1339-43

25. Malinin A, Pokov A, Swaim L, et al. Validation of a VerifyNow-P2Y12 cartridge for monitoring platelet inhibition with clopidogrel. Methods Find Exp Clin Pharmacol 2006;28:315-22

26. von Beckerath N, Pogatsa-Murray G, Wieczorek A, et al. Correlation of a new point-of-care test with conventional optical aggregometry for the assessment of clopidogrel responsiveness. Thromb Haemost 2006;95:910-11

27. Paniccia R, Antonucci E, Gori AM, et al. Different methodologies for evaluating the effect of clopidogrel on platelet function in high-risk coronary artery disease patients. J Thromb Haemost 2007;5:1839-47

28. Jakubowski JA, Payne CD, Li YG, et al. The use of the VerifyNow P2Y12 pointof-care device to monitor platelet function across a range of $\mathrm{P} 2 \mathrm{Y} 12$ inhibition levels following prasugrel and clopidogrel administration. Thromb Haemost 2008;99:409-15

29. Barsky AA, Arora RR. Clopidogrel resistance: myth or reality? J Cardiovasc Pharmacol Ther 2006;11:47-53

30. Prabhakaran S, Wells KR, Lee VH, et al. Prevalence and risk factors for aspirin and clopidogrel resistance in cerebrovascular stenting. AJNR Am J Neuroradiol 2008;29:281-85

31. Patti G, Nusca A, Mangiacapra F, et al. Point-of-care measurement of clopidogrel responsiveness predicts clinical outcome in patients undergoing percutaneous coronary intervention results of the ARMYDA-PRO (Antiplatelet therapy for Reduction of MYocardial Damage during Angioplasty-Platelet Reactivity Predicts Outcome) study. J Am Coll Cardiol 2008;52:1128-33

32. Scandlyn MJ, Stuart EC, Rosenglen RJ. Sex-specific differences in CYP450 isoforms in humans. Expert Opin Drug Metab Toxicol 2008;4:413-24

33. Jeong YH, Lee SW, Choi BR, et al. Randomized comparison of adjunctive cilostazol versus high maintenance dose clopidogrel in patients with high post-treatment platelet reactivity: results of the ACCEL-RESISTANCE (Adjunctive Cilostazol Versus High Maintenance Dose Clopidogrel in Patients With Clopidogrel Resistance) randomized study. J Am Coll Cardiol 2009;53:1101-09

34. Wiviott SD, Braunwald E, McCabe $\mathrm{CH}$, et al. Prasugrel versus clopidogrel in patients with acute coronary syndromes. N Engl J Med 2007;357:2001-15

35. Mega JL, Close SL, Wiviott SD, et al. Cytochrome P-450 polymorphisms and response to clopidogrel. N Engl J Med 2009;360:354-62

36. Simon T, Verstuyft C, Mary-Krause M, et al. Genetic determinants of response to clopidogrel and cardiovascular events. N Engl J Med 2009;360:363-75

37. Collet JP, Hulot JS, Pena A, et al. Cytochrome P450 2C19 polymorphism in young patients treated with clopidogrel after myocardial infarction: a cohort study. Lancet 2009;373:309-17 